(C) 2022, The Authors. Published by Elsevier Inc. and Fass Inc. on behalf of the American Dairy Science Association ${ }^{\circledR}$. This is an open access article under the CC BY license (http://creativecommons.org/licenses/by/4.0/).

\title{
Real-time recombinase-aided amplification with improved propidium monoazide for the rapid detection of viable Escherichia coli 0157:H7 in milk
}

\author{
Dan Mu, ${ }^{1}$ Donggen Zhou, ${ }^{2}$ Guoyang Xie, ${ }^{1}$ Ju Liu, ${ }^{1} \oplus$ Zhengzheng Wang, ${ }^{1}$ Qin Xiong, ${ }^{1}$ and Hengyi Xu ${ }^{1 *}$ (]) \\ ${ }^{1}$ State Key Laboratory of Food Science and Technology, Nanchang University, Nanchang, 330047, PR China \\ ${ }^{2}$ Ningbo International Travel Healthcare Center (Ningbo Customs Port Outpatient Department), Ningbo, 315010, PR China
}

\section{ABSTRACT}

Escherichia coli O157:H7, the causative agent of thrombotic thrombocytopenic purpura and hemolytic uremic syndrome in humans, generates a effective harm to community health because of its high pathogenicity. A real-time recombinase-aided amplification (rRAA) is an emerging method for nucleic acid detection. However, genomic DNA of bacteria could exist in food and the environment for a long time after death and could be amplified by rRAA assay, resulting in false-positive signal; thus, developing a fast and sensitive method is necessary to detect viable foodborne pathogens in food products. In our research, rRAA assay coupled with an enhanced nucleic acid binding dye named improved propidium monoazide (PMAxx) was established and applied in viable E. coli $\mathrm{O} 157: \mathrm{H} 7$ identification in skim milk. The PMAxx could eliminate interference from dead bacteria by permeating impaired membranes and covalently linking to DNA to prevent DNA amplification. The PMAxx-rRAA assay was performed with high sensitivity and good specificity. The PMAxx-rRAA assay could detect as low as $5.4 \times 10^{0} \mathrm{cfu} / \mathrm{mL}$ of viable E. coli $\mathrm{O} 157: \mathrm{H} 7$ in pure culture, and $7.9 \times 10^{0} \mathrm{cfu} / \mathrm{mL}$ of viable E. coli $\mathrm{O} 157: \mathrm{H} 7$ in skim milk. In addition, the PMAxx-rRAA assay was performed in the presence of a high concentration of dead bacteria or nontarget bacteria in skim milk to verify the capacity to resist interference from dead bacteria and nontarget bacteria. Therefore, the established PMAxx-rRAA assay is a valuable tool for the identification of viable $E$. coli O157:H7 in complex food matrix.

Key words: Escherichia coli O157:H7, recombinaseaided amplification, improved propidium monoazide, viable foodborne pathogen, milk

Received July 31, 2021.

Accepted October 21, 2021.

*Corresponding author: kidyxu@163.com or HengyiXu@ncu.edu.cn

\section{INTRODUCTION}

Escherichia coli O157:H7 generates a serious threat to community health because of its high pathogenicity (Rani et al., 2021a), resulting in serious symptoms such as hemolytic uremic syndrome and thrombotic thrombocytopenic purpura (Lin et al., 2019). Escherichia coli O157:H7 can invade human bodies through the ingestion of contaminated food (Chen et al., 2021a). Milk is easily contaminated by bacteria because of its rich nutrition and is regarded as a high-risk food (Han et al., 2018). More than $90 \%$ of the diseases related to dairy product consumption are caused by bacteria (Luo et al., 2017). Moreover, milk is a vital component of diets in many countries, which makes it more likely to lead to infection (Zhao et al., 2021). Escherichia coli O157:H7 is a common foodborne pathogen in milk. Reports have been made of $E$. coli O157:H7 infection outbreaks associated with unpasteurized milk (Honish et al., 2005) or cheese made with unpasteurized milk (Currie et al., 2018). Therefore, developing an effective approach to E. coli $\mathrm{O} 157: \mathrm{H} 7$ identification in milk is necessary.

The traditional culture-based methods are time consuming and labor intensive (Ma et al., 2021), and such methods cannot detect bacteria in the viable but nonculturable (VBNC) state because VBNC cells cannot grow on plates, but they retain virulence or can recover virulence after resuscitation ( $\mathrm{Li}$ et al., 2014). In addressing the bottlenecks of the culture-based method, PCR has been developed in the foodborne pathogen detection field (Gaňová et al., 2021). This is a potential detection tool because of its high-speed detection process and high sensitivity compared with the culture-based method (Li et al., 2021). However, cumbersome equipment is required to control the temperature of denaturation and annealing, which is difficult for point-of-care testing (Mokhtarzadeh et al., 2017). Recently, isothermal nucleic acid amplification has been adopted to detect foodborne pathogens (Lee et al., 2020). Recombinase-aided amplification (RAA), a kind of isothermal nucleic acid amplification method, 
Table 1. The primers and probe sequences used in this study

\begin{tabular}{lll}
$\begin{array}{l}\text { Target } \\
\text { gene }\end{array}$ & Oligonucleotides & Sequence $\left(5^{\prime}-3^{\prime}\right)$ \\
\hline$f l i C$ & $\begin{array}{l}\text { Forward primer } \\
\text { Reverse primer }\end{array}$ & $\begin{array}{l}\text { GTTAACTTTACCATTTGCAAAGGTATATGTAC } \\
\text { GAAATATACTTATAACGCATCGACCAATGATT }\end{array}$ \\
& $\begin{array}{l}\text { CCTTCAGAGTAGCGCCAAGATCTGTCG/i6FAMdT/TG(THF)AG/iBHQ1dT/GCCTGTCGCTAC3'C3 } \\
\text { Spacer }\end{array}$ \\
\hline
\end{tabular}

can be performed at constant temperatures $\left(37-42^{\circ} \mathrm{C}\right.$; Qin et al., 2021) and has a short detection time (less than $20 \mathrm{~min}$ ) and high sensitivity (Shen et al., 2019). Recombinase-aided amplification does not require a complex instrument to provide cyclic temperature (Xue et al., 2020), which makes it more convenient in resource-poor settings than PCR. In this study, the specific fluorescence probe was added in the RAA system to achieve real-time fluorescence analysis.

Previous reports have illustrated that genomic DNA can stay in foods or the environment for a long time after bacterial death and can be normally amplified by the proposed real-time recombinase-aided amplification (rRAA; Gao et al., 2021), potentially overestimating the quantity of viable bacteria in samples and even resulting in false-positive signals (Lv et al., 2020). In other studies, some agents such as ethidium bromide monoazide (EMA) and propidium monoazide (PMA) have been applied in reducing interference from dead bacteria (Roumani et al., 2021). Improved propidium monoazide (PMAxx), a new and improved version of dye PMA, has the same spectral properties and better effects on distinguishing viable bacteria from dead bacteria compared with PMA (Lv et al., 2020). The PMAxx only penetrates the damaged membrane of dead bacteria and then reacts with bases of DNA to suppress DNA amplification (Nocker et al., 2006). However, viable bacteria with intact membranes keep PMAxx out (Dong et al., 2018). PMAxx, combined with quantitative PCR (Zhao et al., 2020), quantitative recombinase polymerase amplification (Lv et al., 2020), and real-time loop-mediated isothermal amplification, has been reported in detection for gram-positive bacteria and gram-negative bacteria (Nocker and Camper, 2009).

In this study, we developed a rRAA assay combined with DNA cross-linking dye named PMAxx for the identification of viable $E$. coli O157:H7. The rRAA is a one-step detection in a closed tube at $39^{\circ} \mathrm{C}$ and completed within $20 \mathrm{~min}$. The PMAxx effectively distinguishes dead bacteria from viable bacteria in terms of membrane integrity. The proposed PMAxx-rRAA was performed simply, rapidly, and sensitively, and the detection limit in E. coli O157:H7 culture was $5.4 \times 10^{0}$ $\mathrm{cfu} / \mathrm{mL}$. Moreover, PMAxx-RAA was applied in skim milk, and the limit of detection (LOD) was $7.9 \times 10^{0}$ $\mathrm{cfu} / \mathrm{mL}$ and was satisfactorily performed in milk where a high concentration of dead bacteria or nontarget bacteria coexisted.

\section{MATERIALS AND METHODS}

\section{Materials, Apparatus, and Reagent Preparation}

Wizard Magnetic DNA Purification System for Food that used to extract genomic DNA was obtained from Promega Corporation; Protease $\mathrm{K}$ was obtained from Tiangen Biotech Co., Ltd. The primers and the specific probe based on the fli $C$ gene were designed by Oligo 6.0 software (Table 1) and prepared by Sangon Biotech; the rRAA kit was supplied by Jiangsu Qitian Gene Technology Co. Ltd.

The fluorescence characterization analysis of PMAxx was photographed by confocal laser scanning microscope (CLSM; Leica TCS SP8); the QT-RAA-F1620 detection system was supplied by Jiangsu Qitian Gene Technology Co. Ltd.

The PMAxx (Bosunlife Co. Ltd.) was deliquesced in sterile water to prepare stock solution at the concentration of $20 \mathrm{mM}$ and stored at $-20^{\circ} \mathrm{C}$ in the dark until used; $2.7 \mathrm{~m} M$ potassium chloride, $10 \mathrm{~m} M$ disodium hydrogen phosphate, $137 \mathrm{~m} M$ sodium chloride, and 2 $\mathrm{m} M$ potassium dihydrogen phosphate were mixed to prepare PBS, and then diluted to prepare a $0.01 M$ PBS solution at $\mathrm{pH}$ of 7.4 .

\section{Bacterial Strains, Culture Medium, and Growth Conditions}

All strains used in this study are listed in Table 2. The bacterial pure culture was prepared by inoculating a single colony grown on Luria Bertani (LB) agar in 5 $\mathrm{mL}$ of $\mathrm{LB}$ broth, and then cultured at $37^{\circ} \mathrm{C}$ in a shake incubator with speed of $180 \mathrm{rpm}$ for $12 \mathrm{~h}$. The culture was washed by $5 \mathrm{~min}$ of centrifugation at $9,600 \times g$ at room temperature and redispersed in sterile PBS. All 
the cells were inoculated on LB agar plates to count the number of viable bacteria.

\section{Preparation of Viable and Dead Cells}

A starting concentration of $10^{9} \mathrm{cfu} / \mathrm{mL}$ of fresh cells was centrifuged and then washed twice with $1 \mathrm{~mL}$ of PBS. Ten-fold series dilutions of bacterial suspension were obtained by adding $50-\mu \mathrm{L}$ cultures of fresh cells into $450 \mu \mathrm{L}$ of PBS. The dead bacterial suspension was prepared by heating the bacterial suspension at $80^{\circ} \mathrm{C}$ for $15 \mathrm{~min}$, and then transferred to refrigerator at $4^{\circ} \mathrm{C}$ for $5 \mathrm{~min}$. All the samples were inoculated and incubated on $\mathrm{LB}$ agar plates at $37^{\circ} \mathrm{C}$ for $24 \mathrm{~h}$ to verify the viability of bacteria.

\section{DNA Extraction}

Genomic DNA was extracted by using the Wizard Magnetic DNA Purification System for Food according to the manufacturer's instructions. Bacterial cells were resuspended in $150 \mu \mathrm{L}$ of bacteria-free water. Then bacterial cells were lysed by shocking magnetic beads under the action of lysis buffer, and silicon-based magnetic beads can adsorb nucleic acid efficiently and specifically. Magnetic beads adsorbing nucleic acid were separated under the applied magnetic field, the supernatant was discarded. The magnetic beads were harvested with wash buffer to remove impurities. The DNA adsorbed on magnetic beads was desorbed and dissolved in elution buffer. The extracted DNA was stored in $-20^{\circ} \mathrm{C}$ until use.

\section{rRAA Assay Condition and Program}

The rRAA assay was preformed according to the manufacturer's instructions of the rRAA kit. Each reaction system included $10 \mu \mathrm{M}$ probe $(0.6 \mu \mathrm{L}), 10 \mu M$ forward primer and reverse primer (each $2.1 \mu \mathrm{L}$ ), sterile water $(12.7 \mu \mathrm{L})$, and reaction buffer $(25 \mu \mathrm{L})$, and then the reagents were blended and transferred into the freeze-dried powder tubes including single-stranded DNA-binding protein, DNA polymerase, and recombinase. The reaction tubes were promptly centrifuged at a speed of $1,200 \times g$ for $30 \mathrm{~s}$ at room temperature, and genomic DNA $(5 \mu \mathrm{L})$ was added; then, $280 \mathrm{mM}$ magnesium acetate solution $(2.5 \mu \mathrm{L})$ was pipetted to the tube cap. Then the samples were blended and centrifuged at once by the QT-RAA-B6100 pre-reaction system. (First, the reaction tubes were centrifuged with speed of $1,200 \times g$ for $10 \mathrm{~s}$ at $39^{\circ} \mathrm{C}$, followed by keeping at a stationary temperature of $39^{\circ} \mathrm{C}$ for $4 \mathrm{~min}$; then, the last procedure was centrifuged at $1,200 \times g$ for $10 \mathrm{~s}$ at $\left.39^{\circ} \mathrm{C}\right)$. The tubes were immediately placed in the QT-RAA-F1620 detection system at a stationary temperature of $39^{\circ} \mathrm{C}$ for $20 \mathrm{~min}$ (Xie et al., 2021).

\section{Fluorescence Characterization of the PMAxx}

Next, $10^{8} \mathrm{cfu} / \mathrm{mL}$ of viable and heat-inactivated $E$. coli O157:H7 was prepared as described above. Subsequently, PMAxx dye was added in samples at a final concentration of $60 \mu \mathrm{M}$ and incubated for $10 \mathrm{~min}$ in the dark, and then the samples were exposed for $10 \mathrm{~min}$, after which all of the samples were washed twice with

Table 2. The bacterial strains used to evaluate specificity of the primer and probe, and the results of the recombinase-aided amplification (RAA) reaction

\begin{tabular}{llll}
\hline Bacterial strain & Strain ID & Source $^{1}$ & RAA results $^{2}$ \\
\hline Escherichia coli O157:H7 & 43888 & ATCC & + \\
Escherichia coli & 44828 & CMCC & + \\
Staphylococcus aureus & 23657 & CICC & - \\
Bacillus cereus & 44102 & CMCC & - \\
Listeria monocytogenes & 26001 & CMCC & - \\
& 26003 & CMCC & - \\
Listeria seeligeri & JDZ102Y & JX-CDC & - \\
Salmonella Enteritidis & 13932 & ATCC & - \\
Salmonella Typhimurium & 19115 & ATCC & - \\
Pseudomonas aeruginosa & 35967 & ATCC & - \\
Bacillus subtilis & 13706 & ATCC & - \\
Monilia albicans & 50115 & CMCC & - \\
Cronobacter sakazakii & 10104 & CMCC & - \\
\hline CMCC & 20445 & CICC & - \\
\hline
\end{tabular}

${ }^{1} \mathrm{CMCC}=$ China Medical Culture Collection (Beijing, China); ATCC = American Type Culture Collection (Manassas, VA); JX-CDC = Jiang Xi Province Center for Disease Control and Prevention, China; CICC = Center of Industrial Culture Collection (Beijing, China).

${ }^{2}$ Results indicate positive or negative signals. 
PBS. Furthermore, $100 \mu \mathrm{L}$ of the sample was pipetted to a microplate reader to measure with 3 replicates the fluorescence intensity of the dead and viable $E$. coli O157:H7 stained with PMAxx. Ten microliters of the sample was pipetted on the microslide and observed by the CLSM.

\section{Optimization of PMAxx Concentration and Exposure Time}

The target bacterial suspensions (approximately $10^{6}$ $\mathrm{cfu} / \mathrm{mL}$ ) were resuspended in PBS and then viable cells and heat-inactivated cells were prepared. The PMAxx was added in target bacterial suspensions to a final concentration of $0,40,120,200$, and $280 \mu \mathrm{M}$, followed by incubation for $10 \mathrm{~min}$ in the dark and exposure to a $500 \mathrm{~W}$ of halogen lamp source for $10 \mathrm{~min}$. Then, the samples were washed 3 times with PBS and resuspended in sterile water. Subsequently, genomic DNA was extracted by a Wizard Magnetic DNA Purification System and then performed for rRAA reaction with 3 replicates.

Next, $10^{6} \mathrm{cfu} / \mathrm{mL}$ of viable bacteria or $10^{6} \mathrm{cfu} / \mathrm{mL}$ of dead bacteria were treated with PMAxx at optimized concentration. During PMAxx treatment, different exposure time $(0,5,10,15,20 \mathrm{~min})$ was performed. Then the genomic DNA were extracted for rRAA reaction. The fluorescent signals were measured with 3 replicates and collected using the QT-RAA-F1620 detection system.

\section{Procedure of PMAxx Treatment}

The bacterial suspensions were incubated with 40 $\mu M$ PMAxx in the dark for 10 min and shaken occasionally, allowing for permeating impaired membrane of dead bacteria. A 500-W halogen lamp source irradiated samples at a distance of $15 \mathrm{~cm}$ for $10 \mathrm{~min}$ to activate the dyes, and the samples were placed on ice to avoid additional inactivation by the heat derived from the halogen lamp. Then the samples were washed 3 times with PBS to remove excess PMAxx and then resuspended in sterile water (Zhou et al., 2019).

\section{Specificity of the Primer and Probe Based on PMAXX-RAA}

The specificity of the primers and the probe was evaluated by performing PMAxx-RAA for 15 nontarget bacteria. All the strains at $10^{6} \mathrm{cfu} / \mathrm{mL}$ were treated with $40 \mu M$ PMAxx and the DNA were extracted for $\mathrm{RAA}$ reaction.

\section{Sensitivity of the PMAxx-RAA Assay in E. Coli 0157:H7 Culture}

To assess the sensitivity of the proposed method, 10fold series dilutions of viable E. coli $\mathrm{O} 157: \mathrm{H} 7 \quad\left(10^{0}\right.$ to $10^{6} \mathrm{cfu} / \mathrm{mL}$ ) were prepared. Each sample was treated with PMAxx under the optimized conditions, then the genomic DNA were extracted for rRAA. Each DNA sample was detected individually and the fluorescent signals were measured with 3 replicates and collected using QT-RAA-F1620 detection system.

\section{Sensitivity of the PMAxx-RAA Assay in Artificially Contaminated Milk}

The PMAxx-RAA assay was further assess the possibility of application in skim milk. The skim milk was purchased from a local supermarket and autoclaved at $115^{\circ} \mathrm{C} / 0.1 \mathrm{MPa}$ for $20 \mathrm{~min}$. Fifty microliters of 10-fold series dilutions of viable $E$. coli $\mathrm{O} 157: \mathrm{H} 7$ was pipetted into $450 \mu \mathrm{L}$ of sterilized skim milk to obtain milk samples including $10^{0}$ to $10^{6} \mathrm{cfu} / \mathrm{mL}$ of viable E. coli O157:H7. The PMAxx with $40 \mu M$ was added into the milk samples and incubated in the dark for $10 \mathrm{~min}$ and exposed for $10 \mathrm{~min}$. The samples were washed by $5 \mathrm{~min}$ of centrifugation with a speed of $9,600 \times g$ at room temperature and resuspended in PBS 3 times. Thirty microliters of protease $\mathrm{K}$ was added in samples at $56^{\circ} \mathrm{C}$ for $30 \mathrm{~min}$ to digest the milk proteins. Then the samples were washed twice with PBS, and redispersed in $150 \mu \mathrm{L}$ of sterile water. Genomic DNA was extracted and the fluorescent signals from samples were measured with 3 replicates and collected using the QT-RAA-F1620 detection system.

\section{Interference Assessment of Dead Bacteria Coexisted in System}

To determine effect of dead bacteria on detection of viable bacteria, the milk samples were performed for PMAxx-rRAA in the presence of a high concentration of dead bacteria. A total of $10^{5} \mathrm{cfu} / \mathrm{mL}$ of dead E. coli O157:H7 was added into $10^{3}$ to $10^{6} \mathrm{cfu} / \mathrm{mL}$ of viable $E$. coli $\mathrm{O} 157: \mathrm{H} 7$ to verify the capacity of resisting interference from dead bacteria in skim milk. The skim milk samples only containing $10^{5} \mathrm{cfu} / \mathrm{mL}$ of viable E. coli O157:H7 were used as the control. The samples were treated with PMAxx under the optimized condition. Genomic DNA were extracted and detected individually with 3 replicates and the fluorescent signals from samples were measured and collected using QT-RAAF1620 detection system. 


\section{Assessment Interference of Nontarget Bacteria Coexisted in System}

To assess effect of nontarget bacteria on detection of target bacteria, the skim milk contained high concentration of nontarget bacteria was performed for PMAxxrRAA. The bacterial suspensions containing (1) only $10^{6} \mathrm{cfu} / \mathrm{mL}$ of $E$. coli $\mathrm{O} 157: \mathrm{H} 7$ at a total volume $500 \mu \mathrm{L}$ of milk sample; (2) $10^{6} \mathrm{cfu} / \mathrm{mL}$ of E. coli $\mathrm{O} 157: \mathrm{H} 7+10^{5}$ $\mathrm{cfu} / \mathrm{mL}$ of $S$. aureus at a total volume $500 \mu \mathrm{L}$ of milk sample; (3) $10^{6} \mathrm{cfu} / \mathrm{mL}$ of E. coli $\mathrm{O} 157: \mathrm{H} 7+10^{5} \mathrm{cfu} /$ $\mathrm{mL}$ of Bacillus cereus at a total volume $500 \mu \mathrm{L}$ of milk sample. The DNA were extracted and performed with 3 replicates for the PMAxx-rRAA assay. The fluorescent signals from each sample were measured and collected using the QT-RAA-F1620 detection system.

\section{Statistical Analysis}

All of the detection procedures were repeated in triplicate. All figures were graphed with GraphPad Prism 8 (GraphPad Software Inc.). Error bars in the figures show the standard deviation from 3 measurements. Data were analyzed for significant differences by SPSS version 19 (SPSS Inc.). Results with $P<0.05$ were considered statistically significant.

\section{RESULTS AND DISCUSSION}

\section{Principle of the PMAxx-rRAA}

Based on the working principle of the method in our research, the PMAxx-rRAA assay for viable E. coli O157:H7 detection was established with 2 steps. The first step is PMAxx treatment. The PMAxx permeates impaired member of dead bacteria in the dark. In bright visible light, the azide group of PMAxx is turned to a nitrene with high reactivity. The nitrene reacts with DNA bases to form an irreversible covalent bond that can inhibit DNA amplification (Nocker et al., 2006). Viable bacteria with intact membrane keeps PMAxx out (Desneux et al., 2015). Therefore, the genomic DNA from viable bacteria is normally amplified, but the amplification of genomic DNA from dead bacteria is suppressed. The second step is the amplification of genomic DNA and read-out of fluorescence signal. The primers integrate with recombinase to form the primerrecombinase complex. Under the action of recombinase, the primers pair with homologous sequences of the genomic DNA, and the target double-stranded DNA is opened and stabilized by single-stranded DNA-binding protein to prevent re-formation of double-stranded DNA immediately (Wang et al., 2020); then, DNA polymerase with displacement activity catalyzes primer ex- tension, and the original strand is displaced to generate amplicons (Zhang et al., 2017). The fluorescent probe paired with amplicon is cleaved, allowing real-time fluorescence screening on the accumulated amplified copies (Londoño et al., 2016). The fluorescence intensity were measured every $20 \mathrm{~s}$. A procedure flowchart is shown in Figure 1.

\section{Fluorescence Characterization of the PMAxx}

The PMAxx could intercalate into genomic DNA and emit fluorescence (Liang et al., 2019), which could be measured by using a microplate reader. As shown in Figure 2(A), a characteristic peak appeared at $610 \mathrm{~nm}$ for heat-inactivated bacteria. However, peak value of the characteristic peak from the viable bacteria was relatively low compared with dead bacteria because PMAxx entered into dead bacteria but could not permeate into viable cells. The average fluorescence intensity at $610 \mathrm{~nm}$ reached 2.9340 for dead bacteria with PMAxx treatment [Figure 2(B)], whereas the average fluorescence intensity of the viable bacteria was only 0.8025. These results proved that PMAxx intercalated into dead bacterial DNA and generated a fluorescence at signal to a noise ratio of 3.6/1. In addition, PMAxx could intercalate into DNA and generate a characteristic fluorescence at an excitation wavelength of $475 \mathrm{~nm}$, showed red color in the image of CLSM in Figure 2(C, D). These results proved that PMAxx was an efficient nucleic acid dye.

\section{Optimization of PMAxx Concentration and Exposure Time}

The concentration of PMAxx was a key factor that affected the suppression effect (Mendes Silva and Domingues, 2015). Excessive PMAxx exerted virulency effects on viable bacteria, which resulted in false-negative detection results, but low concentrations of PMAxx could not completely rule out the amplification signal from dead bacteria (Zhong and Zhao, 2018). Thus, an appropriate PMAxx concentration was required to optimize in order to ensuring that the presence of dead cells would not interfere with the results of viable bacteria detection. As shown in Figure 3(A), the higher the time threshold (TT) value, the higher the inhibitory effect of PMAxx. The TT value is defined as the time when the fluorescence intensity exceeds an arbitrary threshold (Chen et al., 2020). The TT value did not remarkably increase for viable cells, which indicated detection of viable bacteria was affected to a small extent. On the contrary, an evident increase in TT was observed from dead bacteria, which plateaued at $40 \mu M$ PMAxx. 
The significant $(P<0.05)$ differences in TT value of dead bacteria were 0 and $40 \mu M$, but no significant difference between TT value of 40 and $120 \mu M(P>$ $0.05)$ for dead bacteria. The results indicated that the PMAxx could inhibit amplification of DNA from dead bacteria and achieve the best effect at $40 \mu M$ PMAxx. The optimal concentration of PMAxx is different for different species, cells in different growth states, and other biological parameters. Lv et al. (2020) reported that the optimal PMAxx final concentration was $10 \mu M$ for VBNC E. coli O157:H7 in real-time loop-mediated isothermal amplification. Rapid detection of VBNC Cronobacter sakazakii was achieved at $8 \mu M$ PMAxx when combined with droplet digital PCR ( $\mathrm{Lv}$ et al., 2021). Therefore, the optimization is necessary.

The PMAxx intercalated into DNA bases after exposure to strong visible light; thus, exposure time was a critical parameter for PMAxx treatment. The exposure not only activated the dye to react with bases of nucleic acids but also inactivated any excess dye by forming hydroxyl amines (Yuan et al., 2018). Based on the results of optimization [Figure 3(B)], TT values of dead bacteria increased with increased exposure time and reached a plateau at $5 \mathrm{~min}$, and the TT value decreased when the exposure time exceeded $10 \mathrm{~min}$. The TT value at $10 \mathrm{~min}$ was similar to that at 5 min of exposure time. There were no significant difference between the TT value at 5 and $10 \mathrm{~min}(P>0.05)$. To ensure the excess PMAxx dye was completely photolyzed without affecting the detection results, 10 min of exposure time was selected ( $\mathrm{Lv}$ et al., 2020). The TT value of viable cells did not increase remarkably, indicating that the detection of viable bacteria was not affected.

Therefore, in this study, the most optimum concentration was $40 \mu M$ PMAxx, and 10 min of exposure was selected as the optimum exposure time, which did not affect the detection signals of the viable bacteria and suppressed the signal amplification from the dead cells to the greatest extent.

\section{Specificity of the Primer and Probe Based on PMAxx-rRAA}

Seventeen strains were used to evaluate the specificity of the primers and the probe. The results are shown in Table 2; only the 2 E. coli $\mathrm{O} 157: \mathrm{H} 7$ showed a positive signal in the presence of fliC (Zhou et al., 2017). The 15 nontarget bacteria showed a negative signal. The primers and probe showed good specificity based on the PMAxx-rRAA.

\section{Sensitivity of the PMAxx-rRAA Assay in Pure Culture and in Spiked Milk Matrix}

The PMAxx-rRAA assay with optimized parameters in 10-fold series dilutions of E. coli $\mathrm{O} 157: \mathrm{H} 7$ were performed to determine the sensitivity. Based on the fluorescent amplification curves and $\mathrm{TT}$ values shown

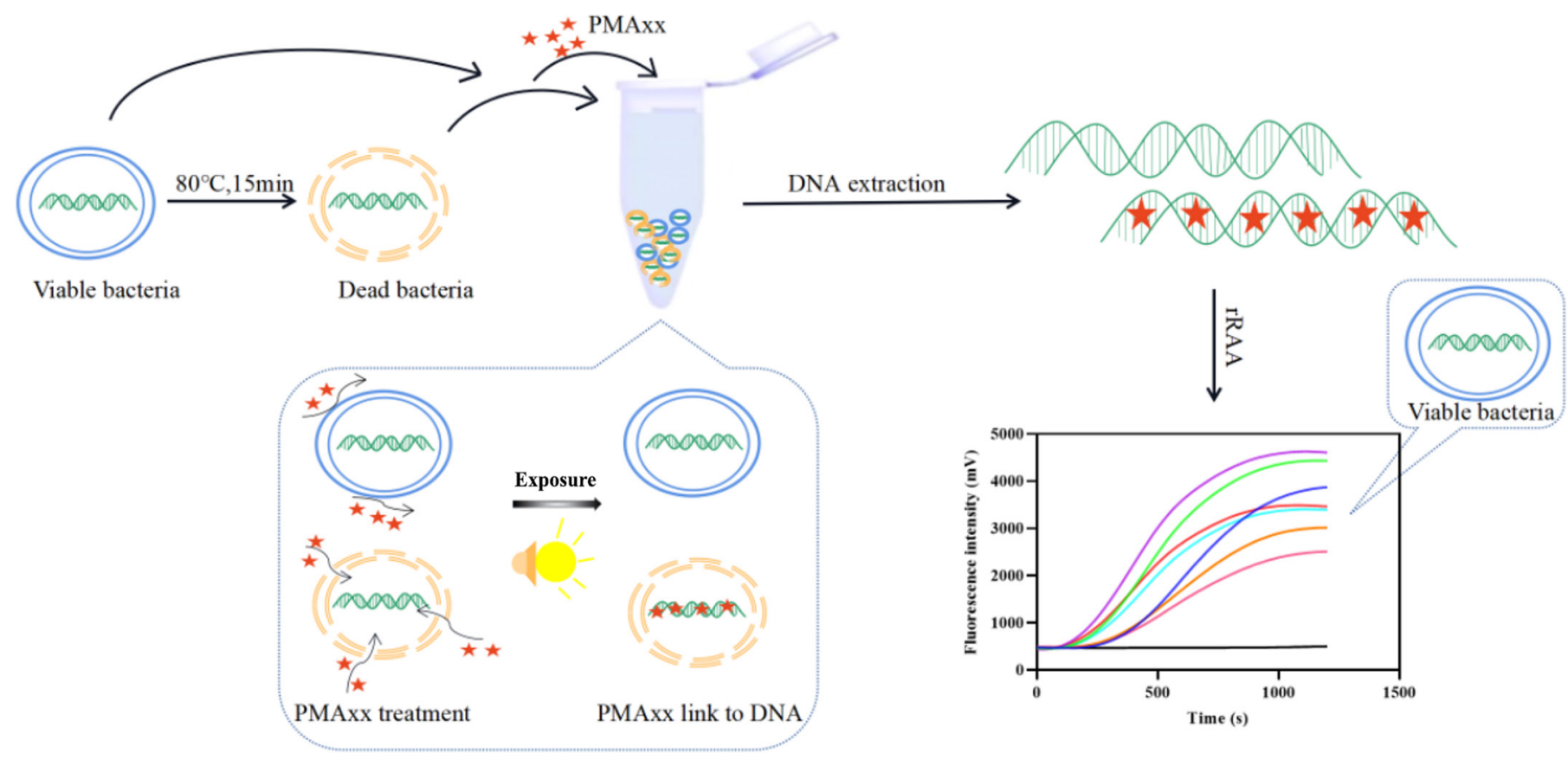

Figure 1. Overview of the detection process of Escherichia coli O157:H7 based on propidium monoazide (PMAxx)-real-time recombinaseaided amplification (rRAA) assay. 

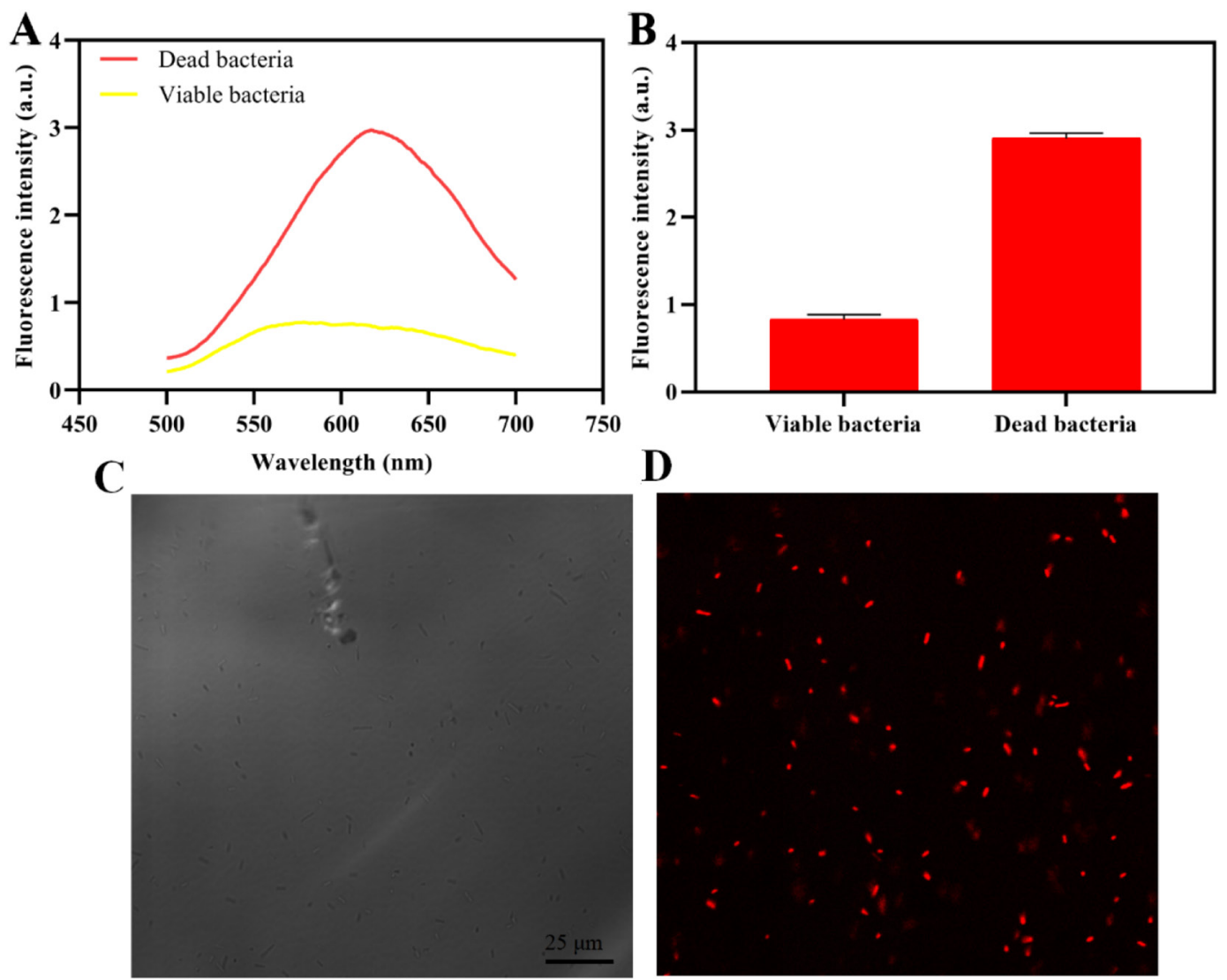

Figure 2. Characterization of Escherichia coli O157:H7 treated with propidium monoazide (PMAxx). (A) Fluorescence spectrum of the dead bacteria and viable bacteria stained with PMAxx; (B) average fluorescence intensity of the dead bacteria and viable bacteria stained with PMAxx; (C) confocal laser scanning microscope (CLSM) images of E. coli O157:H7 in a bright field; (D) CLSM images of dead E. coli O157:H7 stained with PMAxx and shown in red. Error bars represent SD from 3 independent experiments.

in Figure 4, $5.4 \times 10^{0}$ to $5.4 \times 10^{6} \mathrm{cfu} / \mathrm{mL}$ of $E$. coli O157:H7 could generate fluorescent signals, and the $\mathrm{TT}$ value decreased as the concentration of bacteria increased. In addition, the control without E. coli
O157:H7 could not generate a visible fluorescent signal and there was no TT value at 20 min (data not shown). Therefore, the PMAxx-rRAA could detect as low as 5.4 $\times 10^{0} \mathrm{cfu} / \mathrm{mL}$ of viable E. coli $\mathrm{O} 157: \mathrm{H} 7$.
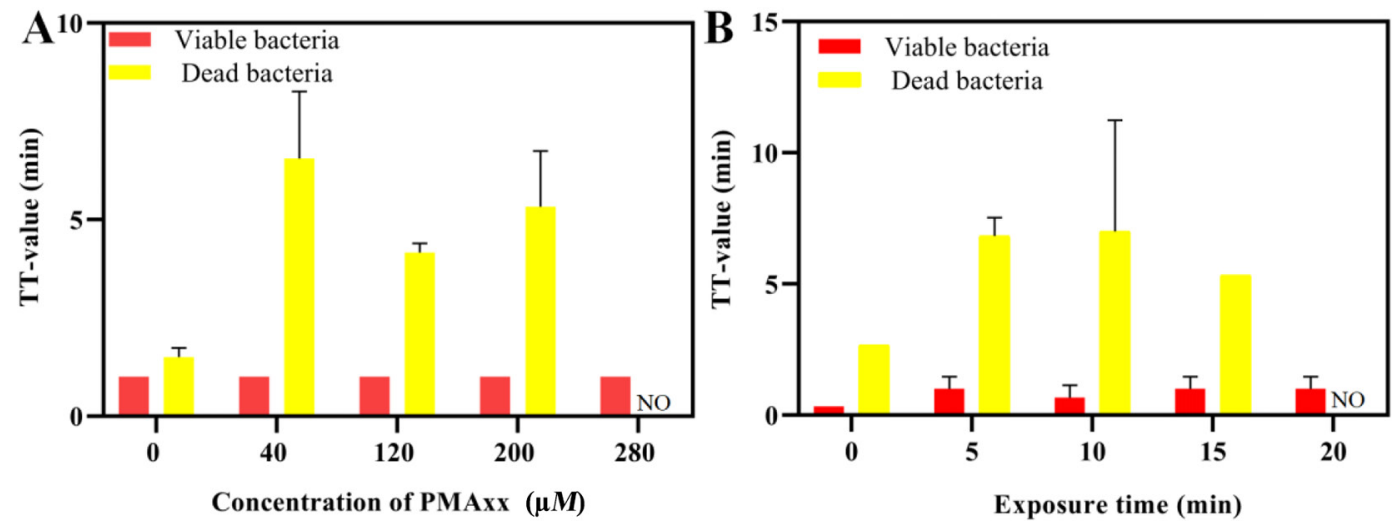

Figure 3. Optimization of the propidium monoazide (PMAxx) treatment condition. (A) Effect of PMAxx concentration, the result of "NO" is defined as no time threshold (TT) value within $20 \mathrm{~min}$; and (B) effect of exposure time, the "NO" result is defined as no time threshold value within 20 min. Error bars represent SD from 3 independent experiments; some error bars are too short to be visible. 

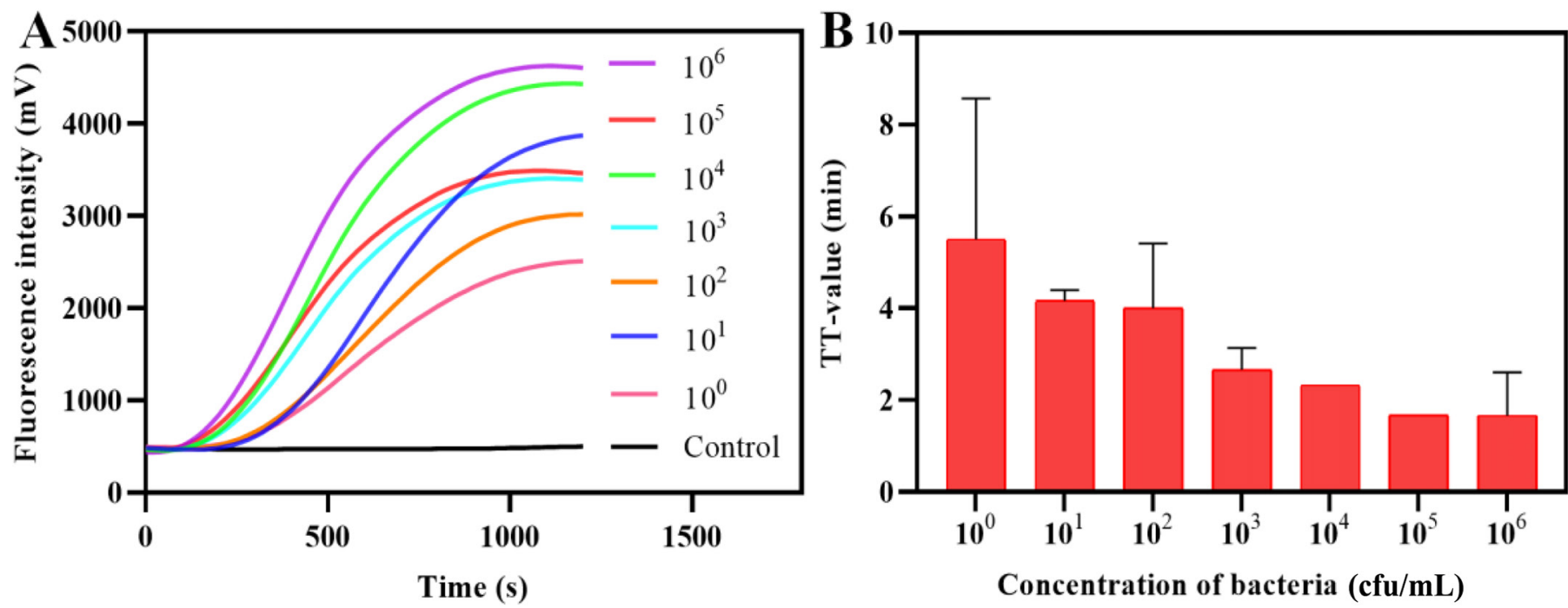

Figure 4. Sensitivity of the propidium monoazide (PMAxx)-recombinase-aided amplification (RAA) assay in pure culture. (A) Amplification curves from a series of bacterial dilutions ranging from $10^{6}$ to $10^{0} \mathrm{cfu} / \mathrm{mL}$ of Escherichia coli $\mathrm{O} 157: \mathrm{H} 7$ and (B) corresponding time threshold values. Error bars represent SD from 3 independent experiments; some error bars are too short to be visible.

Milk samples including $7.9 \times 10^{0} \mathrm{cfu} / \mathrm{mL}$ to $7.9 \times 10^{6}$ $\mathrm{cfu} / \mathrm{mL}$ of E. coli O157:H7 were prepared to explore the application of PMAxx-rRAA. The milk protein might interfere with rRAA; therefore, protease $\mathrm{K}$ was used to digest proteins of milk. According to the results, the PMAxx-rRAA could be performed well in milk treated with protease K. As shown in Figure 5, the fluorescence amplification curves appeared from $7.9 \times 10^{0} \mathrm{cfu} / \mathrm{mL}$ to $7.9 \times 10^{6} \mathrm{cfu} / \mathrm{mL}$, but the control without target bacteria did not show visible amplification signal. The $\mathrm{TT}$ values gradually decreased with the increase of bac- terial concentration, and there was no TT value in the control (data not shown). These results confirmed that the PMAxx-rRAA could be applied in milk samples, and the LOD in milk samples was $7.9 \times 10^{\circ} \mathrm{cfu} / \mathrm{mL}$.

\section{Assessment Interference of Viable/Dead Bacteria Coexisted in the System}

Mixtures containing viable E. coli $\mathrm{O} 157: \mathrm{H} 7\left(10^{3}-10^{6}\right.$ $\mathrm{cfu} / \mathrm{mL}$ ) and $10^{5} \mathrm{cfu} / \mathrm{mL}$ of dead E. coli $\mathrm{O} 157: \mathrm{H} 7$ were prepared to assess the effect of high concentrations of
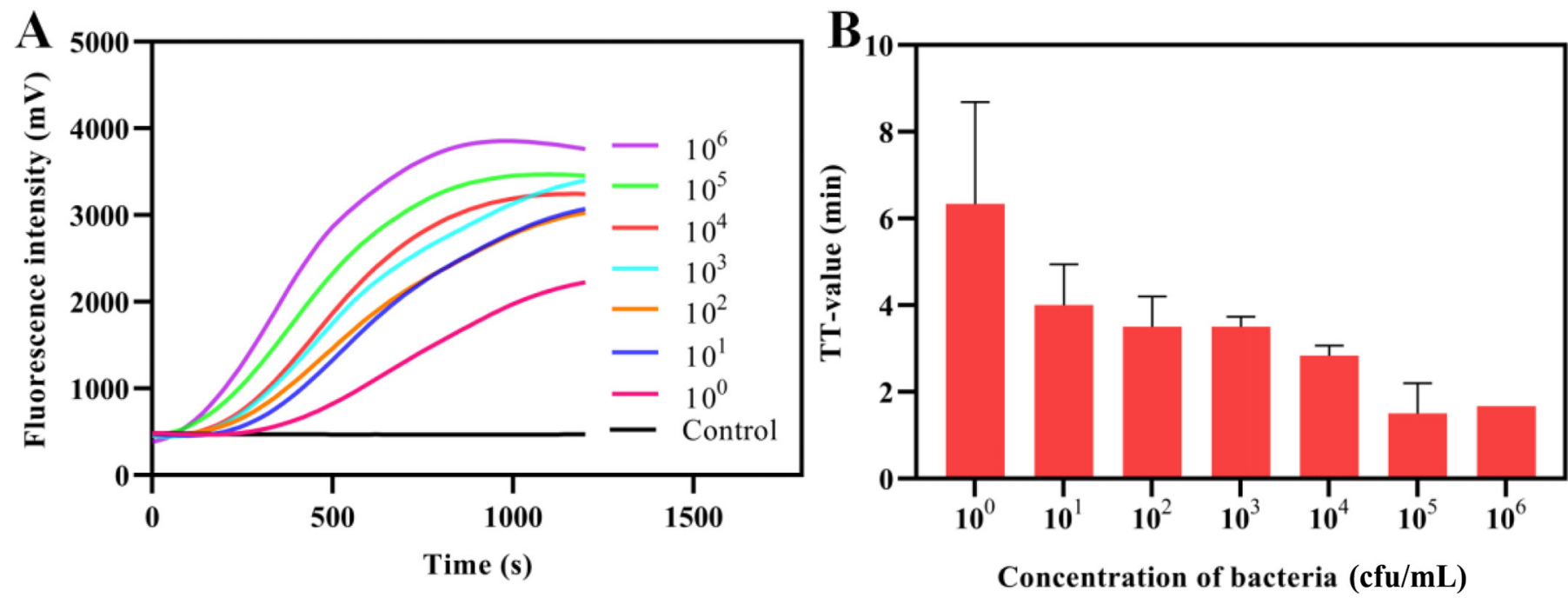

Figure 5. Sensitivity of the propidium monoazide (PMAxx)-recombinase-aided amplification (RAA) assay in skim milk. (A) Amplification curves from a series of bacterial dilutions ranging from $10^{6}$ to $10^{0} \mathrm{cfu} / \mathrm{mL}$ of Escherichia coli O157:H7 and (B) corresponding time threshold (TT) values. Error bars represent SD from 3 independent experiments; some error bars are too short to be visible. 


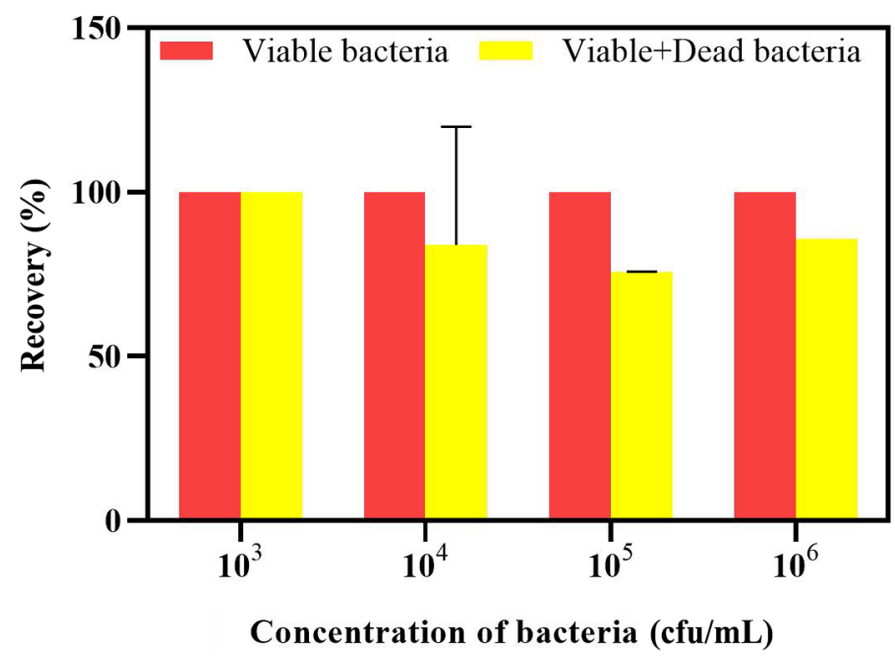

Figure 6. Application of the propidium monoazide (PMAxx)recombinase-aided amplification (RAA) method in the presence of $10^{5}$ cfu/mL of dead Escherichia coli O157:H7 in milk. Error bars represent SD from 3 independent experiments; some error bars are too short to be visible.

dead E. coli $\mathrm{O} 157: \mathrm{H} 7$ on detection of viable bacteria. The samples were treated with $40 \mu M$ PMAxx and exposed for $10 \mathrm{~min}$ and then the genomic DNA was extracted to perform rRAA. Based on the results in Figure 6, the recovery of the sample that only contained viable bacteria was defined as $100 \%$, and the ratio of the corresponding $\mathrm{TT}$ value of the mixture to the average of the TT value of viable bacteria was defined as the recovery. The closer the recovery is to $100 \%$, the smaller the effect of dead bacteria on detection of viable bacteria. The results in Figure 6 indicated that even a high concentration of dead bacteria will only affect the detection of viable bacteria slightly. Therefore, the PMAxx-rRAA can selectively detect viable bacteria in the presence of a high concentration of dead bacteria.

\section{Interference of Nontarget Bacteria Based on the PMAxx-rRAA Assay}

The mixtures were prepared by mixing E. coli O157:H7 with other species in skim milk to verify whether nontarget bacteria co-existing in the samples could interfere with the detection results of target bacteria. The sample only included $10^{5} \mathrm{cfu} / \mathrm{mL}$ of $E$. coli $\mathrm{O} 157: \mathrm{H7}$, which served as the control. Based on the results in Figure 7, the similar reaction curve and satisfactory recovery indicated the nontarget bacteria only slightly interfered with the detection results of $E$. coli O157:H7. The reason for this is that the nontarget sequence interfered with the primer paired with the target sequence. In our research, we defined the average TT values of pure target bacteria as $100 \%$ of the recovery (group 1). The recovery of group 2 and group 3 was a ratio of the corresponding TT values to the average TT values of group 1 (Xie et al., 2021).

\section{CONCLUSIONS}

We established a rRAA assay coupled with PMAxx for identification of viable E. coli $\mathrm{O} 157: \mathrm{H} 7$ in skim milk. The proposed method showed outstanding advantages in sensitivity, detection time, and viable or dead determination compared with DNA-based isothermal methods (Table 3 ). The improved DNA cross-linking dye named PMAxx could intercalate into the genomic DNA and inhibit its duplication. The PMAxx only permeates into dead bacteria with impaired membranes and is kept out of viable bacteria. Therefore, the proposed PMAxx-rRAA could effectively detect viable $E$. coli O157:H7. The rRAA showed good specificity and efficiency. The detection could be completed within 20 min, and it did not require complicated equipment for the thermal cycle. The proposed PMAxx-rRAA assay showed a good LOD of $5.4 \times 10^{0} \mathrm{cfu} / \mathrm{mL}$ in pure culture and $7.9 \times 10^{0} \mathrm{cfu} / \mathrm{mL}$ in milk. Moreover, the method performed satisfactorily in milk in the presence of dead or nontarget bacteria.

\section{ACKNOWLEDGMENTS}

The work was supported by the China National Key R\&D Program during the 13th Five-year Plan Period (2019YFF0302501), Natural Science Foundation of Zhejiang Province, China (LY16H260004), Research Foundation from Academic and Technical Lead-

Table 3. Comparisons between different DNA-based isothermal methods for Escherichia coli O157:H7 detection

\begin{tabular}{|c|c|c|c|c|}
\hline Detection method $^{1}$ & Detection time & Limit of detection $(\mathrm{cfu} / \mathrm{mL})$ & Vitality determination & Reference \\
\hline $\mathrm{RCA}$ & $30 \mathrm{~min}$ & $4 \times 10^{3}$ & No & Jiang et al., 2019 \\
\hline $\mathrm{HDA}$ & $1 \mathrm{~h}$ & $10^{2}$ & No & Rani et al., 2021b \\
\hline SDA & $50 \min$ & 10 & No & Wu et al., 2015 \\
\hline
\end{tabular}

${ }^{1}$ Rti-LAMP = real-time loop-mediated isothermal amplification; RCA = rolling circle amplification; HDA = helicase-dependent amplification; $\mathrm{HCR}=$ hybridization chain reaction; SDA = strand displacement amplification. 

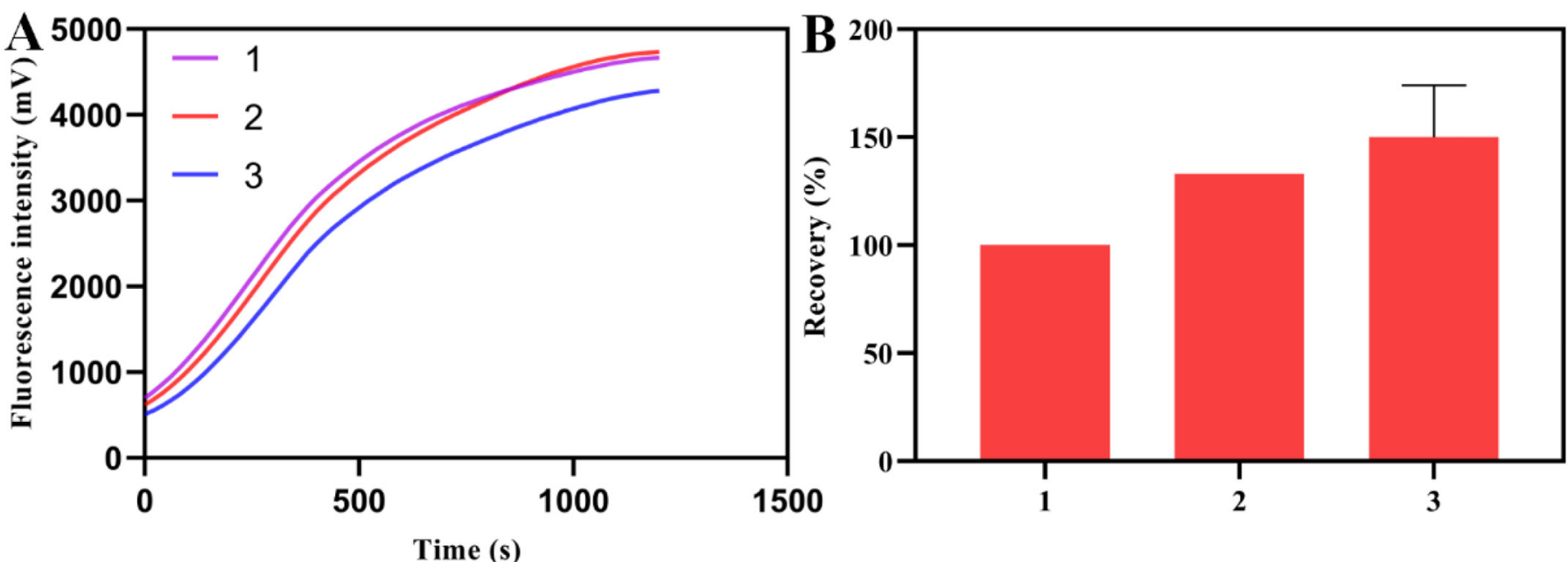

Figure 7. Interference of nontarget bacteria $\left(10^{5} \mathrm{cfu} / \mathrm{mL}\right.$ ) based on the propidium monoazide (PMAxx)-recombinase-aided amplification (RAA) assay. (A) Amplification curves; (B) corresponding recovery, 1: only $10^{6} \mathrm{cfu} / \mathrm{mL}$ of Escherichia coli O157:H7; 2: 10 ${ }^{6} \mathrm{cfu} / \mathrm{mL}$ of E. coli O157:H7 $+10^{5} \mathrm{cfu} / \mathrm{mL}$ of Staphylococcus aureus at a; $3: 10^{6} \mathrm{cfu} / \mathrm{mL}$ of E. coli O157:H7 $+10^{5} \mathrm{cfu} / \mathrm{mL}$ of Bacillus cereus. Error bars represent SD from 3 independent experiments; some error bars are too short to be visible.

ers of Major Disciplines in Jiangxi Province, China (20194BCJ22004), and Research Project of State Key Laboratory of Food Science and Technology, Nanchang University, China (SKLF-ZZB-202133). The authorship contributions are as follows: Dan Mu: methodology, data curation, and writing of the original draft; Donggen Zhou: resources, investigation, and supervision; Guoyang Xie: investigation and methodology; Ju Liu and Zhengzheng Wang: formal analysis; Qin Xiong: resources; and Hengyi Xu: methodology, conceptualization, and supervision. The authors have not stated any conflicts of interest.

\section{REFERENCES}

Chen, G., R. Chen, S. Ding, M. Li, J. Wang, J. Zou, F. Du, J. Dong, X. Cui, X. Huang, Y. Deng, and Z. Tang. 2020. Recombinase assisted loop-mediated isothermal DNA amplification. Analyst (Lond.) 145:440-444. https://doi.org/10.1039/C9AN01701A.

Chen, H., Y.-K. Li, T.-T. Zhang, Y. Bi, M. Shu, C. Zhong, K.-J. Tang, and G.-P. Wu. 2021a. A novel real-time loop-mediated isothermal amplification combined with immunomagnetic beads separation and ethidium bromide monoazide treatment for rapid and ultrasensitive detection of viable Escherichia coli O157:H7 in milk. Food Anal. Methods 14:944-956. https://doi.org/10.1007/s12161 -020-01932-y.

Chen, H., Y.-K. Li, T.-T. Zhang, Y. Bi, M. Shu, C. Zhong, K.-J. Tang, and G.-P. Wu. 2021b. A novel real-time loop-mediated isothermal amplification combined with immunomagnetic beads separation and ethidium bromide monoazide treatment for rapid and ultrasensitive detection of viable Escherichia coli O157:H7 in milk. Food Anal. Methods 14:944-956. https://doi.org/10.1007/s12161 -020-01932-y.

Currie, A., E. Galanis, P. A. Chacon, R. Murray, L. Wilcott, P. Kirkby, L. Honish, K. Franklin, J. Farber, R. Parker, S. Shyng, D. Sharma, L. Tschetter, L. Hoang, L. Chui, A. Pacagnella, J. Wong, J. Pritchard, A. Kerr, M. Taylor, V. Mah, and J. Flint. 2018. Outbreak of Escherichia coli O157:H7 infections linked to aged raw milk Gouda cheese, Canada, 2013. J. Food Prot. 81:325-331. https: //doi.org/10.4315/0362-028X.JFP-17-283.

Desneux, J., M. Chemaly, and A.-M. Pourcher. 2015. Experimental design for the optimization of propidium monoazide treatment to quantify viable and non-viable bacteria in piggery effluents. BMC Microbiol. 15:164. https://doi.org/10.1186/s12866-015-0505-6.

Dong, L., H. Liu, L. Meng, M. Xing, J. Wang, C. Wang, H. Chen, and N. Zheng. 2018. Quantitative PCR coupled with sodium dodecyl sulfate and propidium monoazide for detection of viable Staphylococcus aureus in milk. J. Dairy Sci. 101:4936-4943. https://doi .org/10.3168/jds.2017-14087.

Gaňová, M., H. Zhang, H. Zhu, M. Korabečná, and P. Neužil. 2021. Multiplexed digital polymerase chain reaction as a powerful diagnostic tool. Biosens. Bioelectron. 181:113155. https://doi.org/10 $.1016 /$ j.bios.2021.113155.

Gao, S., C. Sun, H. Hong, R. Gooneratne, A. Mutukumira, and X. Wu. 2021. Rapid detection of viable Cronobacter sakazakii in powdered infant formula using improved propidium monoazide (PMAxx) and quantitative recombinase polymerase amplification (qRPA) assay. Food Control 124:107899. https://doi.org/10.1016/ j.foodcont.2021.107899.

Han, J., L. Zhang, L. Hu, K. Xing, X. Lu, Y. Huang, J. Zhang, W. Lai, and T. Chen. 2018. Nanozyme-based lateral flow assay for the sensitive detection of Escherichia coli O157:H7 in milk. J. Dairy Sci. 101:5770-5779. https://doi.org/10.3168/jds.2018-14429.

Honish, L., G. Predy, N. Hislop, L. Chui, K. Kowalewska-Grochowska, L. Trottier, C. Kreplin, and I. Zazulak. 2005. An outbreak of E. coli O157:H7 Hemorrhagic colitis associated with unpasteurized Gouda cheese. Can. J. Public Health 96:182-184. https://doi.org/ $10.1007 / \mathrm{BF} 03403686$.

Jiang, Y., S. Li, Z. Qiu, T. Le, S. Zou, and X. Cao. 2019. Rolling circle amplification and its application in microfluidic systems for Escherichia coli O157:H7 detections. J. Food Saf. 39:e12671. https:// doi.org/10.1111/jfs.12671.

Lee, S., H. Jang, H. Y. Kim, and H. G. Park. 2020. Three-way junction-induced isothermal amplification for nucleic acid detection. Biosens. Bioelectron. 147:111762. https://doi.org/10.1016/j.bios .2019.111762.

Li, D., L. Liu, Q. Huang, T. Tong, Y. Zhou, Z. Li, Q. Bai, H. Liang, and L. Chen. 2021. Recent advances on aptamer-based biosensors for detection of pathogenic bacteria. World J. Microbiol. Biotechnol. 37:45. https://doi.org/10.1007/s11274-021-03002-9. 
Li, L., N. Mendis, H. Trigui, J. D. Oliver, and S. P. Faucher. 2014. The importance of the viable but non-culturable state in human bacterial pathogens. Front. Microbiol. 5:258. https://doi.org/10.3389/ fmicb.2014.00258.

Liang, T., X. Wu, B. Chen, J. Liu, Z. P. Aguilar, and H. Xu. 2020. The PCR-HCR dual signal amplification strategy for ultrasensitive detection of Escherichia coli O157:H7 in milk. Lebensm. Wiss. Technol. 130:109642. https://doi.org/10.1016/j.lwt.2020.109642.

Liang, T., P. Zhou, B. Zhou, Q. Xu, Z. Zhou, X. Wu, Z. P. Aguilar, and H. Xu. 2019. Simultaneous quantitative detection of viable Escherichia coli O157:H7, Cronobacter spp., and Salmonella spp. using sodium deoxycholate-propidium monoazide with multiplex real-time PCR. J. Dairy Sci. 102:2954-2965. https://doi.org/10 $.3168 /$ jds.2018-15736.

Lin, L., X. Wang, C. Li, and H. Cui. 2019. Inactivation mechanism of E. coli O157:H7 under ultrasonic sterilization. Ultrason. Sonochem. 59:104751. https://doi.org/10.1016/j.ultsonch.2019.104751.

Londoño, M. A., C. L. Harmon, and J. E. Polston. 2016. Evaluation of recombinase polymerase amplification for detection of begomoviruses by plant diagnostic clinics. Virol. J. 13:48. https://doi.org/ 10.1186/s12985-016-0504-8.

Luo, K., L. Hu, Q. Guo, C. Wu, S. Wu, D. Liu, Y. Xiong, and W. Lai. 2017. Comparison of 4 label-based immunochromatographic assays for the detection of Escherichia coli O157:H7 in milk. J. Dairy Sci. 100:5176-5187. https://doi.org/10.3168/jds.2017-12554.

Lv, X., X. Gu, L. Wang, X. He, C. He, J. Zhang, and L. Zhao. 2021. Rapid and absolute quantification of VBNC Cronobacter sakazakii by PMAxx combined with single intact cell droplet digital PCR in infant foods. Lebensm. Wiss. Technol. 145:111388. https://doi .org/10.1016/j.lwt.2021.111388.

Lv, X., L. Wang, J. Zhang, H. Zeng, X. Chen, L. Shi, H. Cui, X. He, and L. Zhao. 2020. Rapid and sensitive detection of VBNC Escherichia coli O157: H7 in beef by PMAxx and real-time LAMP. Food Control 115:107292. https://doi.org/10.1016/j.foodcont.2020 .107292 .

Ma, X., W. Ding, C. Wang, H. Wu, X. Tian, M. Lyu, and S. Wang. 2021. DNAzyme biosensors for the detection of pathogenic bacteria. Sens. Actuators B Chem. 331:129422. https://doi.org/10 .1016/j.snb.2020.129422.

Mendes Silva, D., and L. Domingues. 2015. On the track for an efficient detection of Escherichia coli in water: A review on PCRbased methods. Ecotoxicol. Environ. Saf. 113:400-411. https://doi .org/10.1016/j.ecoenv.2014.12.015.

Mokhtarzadeh, A., R. Eivazzadeh-Keihan, P. Pashazadeh, M. Hejazi, N. Gharaatifar, M. Hasanzadeh, B. Baradaran, and M. de la Guardia. 2017. Nanomaterial-based biosensors for detection of pathogenic virus. Trends Analyt. Chem. 97:445-457. https://doi.org/10 .1016/j.trac.2017.10.005.

Nocker, A., and A. K. Camper. 2009. Novel approaches toward preferential detection of viable cells using nucleic acid amplification techniques. FEMS Microbiol. Lett. 291:137-142.

Nocker, A., C.-Y. Cheung, and A. K. Camper. 2006. Comparison of propidium monoazide with ethidium monoazide for differentiation of live vs. dead bacteria by selective removal of DNA from dead cells. J. Microbiol. Methods 67:310-320. https://doi.org/10.1016/ j.mimet.2006.04.015.

Qin, Z., L. Xue, W. Cai, J. Gao, Y. Jiang, J. Yang, Y. Liang, L. Wang, J. Zhang, Y. Hu, and Q. Wu. 2021. Development of a recombinaseaided amplification assay for rapid detection of human norovirus GII.4. BMC Infect. Dis. 21:248. https://doi.org/10.1186/s12879 -021-05942-x.

Rani, A., V. B. Ravindran, A. Surapaneni, N. Mantri, and A. S. Ball. 2021a. Review: Trends in point-of-care diagnosis for Escherichia coli O157:H7 in food and water. Int. J. Food Microbiol. 349:109233. https://doi.org/10.1016/j.ijfoodmicro.2021.109233.

Rani, A., V. B. Ravindran, A. Surapaneni, N. Mantri, and A. S. Ball. 2021b. Review: Trends in point-of-care diagnosis for Escherichia coli O157:H7 in food and water. Int. J. Food Microbiol. 349:109233. https://doi.org/10.1016/j.ijfoodmicro.2021.109233.
Roumani, F., S. Azinheiro, J. Carvalho, M. Prado, and A. GarridoMaestu. 2021. Loop-mediated isothermal amplification combined with immunomagnetic separation and propidium monoazide for the specific detection of viable Listeria monocytogenes in milk products, with an internal amplification control. Food Control 125:107975. https://doi.org/10.1016/j.foodcont.2021.107975.

Shen, X. X., F. Qiu, L.-P. Shen, T. Yan, M. Zhao, J.-J. Qi, C. Chen, L. Zhao, L. Wang, Z. Feng, and X. Ma. 2019. A rapid and sensitive recombinase aided amplification assay to detect hepatitis $\mathrm{B}$ virus without DNA extraction. BMC Infect. Dis. 19:229. https:// doi.org/10.1186/s12879-019-3814-9.

Wang, W., C. Wang, Y. Bai, P. Zhang, S. Yao, J. Liu, and T. Zhang. 2020. Establishment of reverse transcription recombinase-aided amplification-lateral-flow dipstick and real-time fluorescencebased reverse transcription recombinase-aided amplification methods for detection of the Newcastle disease virus in chickens. Poult. Sci. 99:3393-3401. https://doi.org/10.1016/j.psj.2020.03.018.

Wu, W., S. Zhao, Y. Mao, Z. Fang, X. Lu, and L. Zeng. 2015. A sensitive lateral flow biosensor for Escherichia coli O157:H7 detection based on aptamer mediated strand displacement amplification. Anal. Chim. Acta 861:62-68. https://doi.org/10.1016/j.aca.2014 .12 .041 .

Xie, G., D. Zhou, G. Zhao, X. Feng, Z. P. Aguilar, and H. Xu. 2021. Recombinase aided amplification with photoreactive DNA-binding dye for rapid detection of viable Staphylococcus aureus. Lebensm. Wiss. Technol. 135:110249. https://doi.org/10.1016/j.lwt.2020 .110249.

Xue, G., S. Li, H. Zhao, C. Yan, Y. Feng, J. Cui, T. Jiang, and J. Yuan. 2020. Use of a rapid recombinase-aided amplification assay for Mycoplasma pneumoniae detection. BMC Infect. Dis. 20:79. https://doi.org/10.1186/s12879-019-4750-4.

Yuan, Y., G. Zheng, M. Lin, and A. Mustapha. 2018. Detection of viable Escherichia coli in environmental water using combined propidium monoazide staining and quantitative PCR. Water Res. 145:398-407. https://doi.org/10.1016/j.watres.2018.08.044.

Zhang, X., L. Guo, R. Ma, L. Cong, Z. Wu, Y. Wei, S. Xue, W. Zheng, and S. Tang. 2017. Rapid detection of Salmonella with recombinase aided amplification. J. Microbiol. Methods 139:202-204. https://doi.org/10.1016/j.mimet.2017.06.011.

Zhao, L., X. Lv, X. Cao, J. Zhang, X. Gu, H. Zeng, and L. Wang. 2020. Improved quantitative detection of VBNC Vibrio parahaemolyticus using immunomagnetic separation and PMAxx-qPCR. Food Control 110:106962. https://doi.org/10.1016/j.foodcont.2019.106962.

Zhao, Y., Y. Li, P. Zhang, Z. Yan, Y. Zhou, Y. Du, C. Qu, Y. Song, D. Zhou, S. Qu, and R. Yang. 2021. Cell-based fluorescent microsphere incorporated with carbon dots as a sensitive immunosensor for the rapid detection of Escherichia coli $\mathrm{O} 157$ in milk. Biosens. Bioelectron. 179:113057. https://doi.org/10.1016/j.bios .2021.113057.

Zhong, J., and X. Zhao. 2018. Detection of viable but non-culturable Escherichia coli O157:H7 by PCR in combination with propidium monoazide. 3 Biotech 8:28. https://doi.org/10.1007/s13205-017 $-1052-7$.

Zhou, B., T. Liang, Z. Zhan, R. Liu, F. Li, and H. Xu. 2017. Rapid and simultaneous quantification of viable Escherichia coli O157:H7 and Salmonella spp. in milk through multiplex real-time PCR. J. Dairy Sci. 100:8804-8813. https://doi.org/10.3168/jds.2017-13362.

Zhou, P., G. Xie, T. Liang, B. Yu, Z. Aguilar, and H. Xu. 2019. Rapid and quantitative detection of viable emetic Bacillus cereus by PMA-qPCR assay in milk. Mol. Cell. Probes 47:101437. https:// doi.org/10.1016/j.mcp.2019.101437.

\section{ORCIDS}

Ju Liu (1) https://orcid.org/0000-0002-5815-9482

Hengyi Xu ๑ https://orcid.org/0000-0003-0457-9665 